\title{
Giá trị nhân văn cao đẹp trong lời kêu gọi thi đuaái quốc với nhiệm vụ giáo dục đạo đức cách mạng cho thanh niên hiện nay
}

\author{
Bùi Bạch Đằng ${ }^{a}$, Trần Thế Khanh ${ }^{a}$ \\ ${ }^{a}$ Trường Đại học Chính trị, Bộ Quốc Phòng \\ *Email:bachdangk2@gmail.com
}

\section{Thông tin bài viết}

Ngày nhận bài:

20/4/2018

Ngày duyệt đăng:

$10 / 9 / 2018$

Tù khoá:

Ho Chi Minh, patriotic competition, human values.

\section{Tóm tắt}

Cách đây 80 năm, giữa thời kỳ gian khổ, ác liệt trong cuộc kháng chiến chống thực dân Pháp xâm lược, theo sáng kiến của Chủ tịch Hồ Chí Minh, ngày 27/3/1948, Ban Chấp hành Trung ương Đảng đã ra Chỉ thị đẩy mạnh phong trào thi đua ái quốc nhằm động viên mọi lực lượng tham gia kháng chiến và kiến quốc. Theo đó, ngày 11/6/1948, Chủ tịch Hồ Chí Minh ra Lời kêu gọi thi đua ái quốc. Đây là bản hùng ca bất hủ, chất chứa và đậm sâu giá trị nhân văn sâu sắc.

\section{1. Đặt vấn đề}

Cách đây 80, vào mùa xuân năm 1948, khi cuộc kháng chiến chống thực dân Pháp xâm lược bước vào giai đoạn cam go, ác liệt, tình thế đất nước gặp muôn vàn khó khăn. Nhằm kêu gọi toàn thể dân tộc đứng lên đấu tranh, đem hết tài năng và sức lực, tinh thần và lực lượng cống hiến cho cách mạng, ngày 11/6/1948, Chủ tịch Hồ Chí Minh ra Lời kêu gọi thi đua ái quốc - Bản hùng ca bất hủ, chất chứa và đậm sâu giá trị nhân văn sâu sắc.

\section{Nội dung}

\subsection{Giá trị nhân văn cao đẹp trong Lò̀i kêu gọi thi đua ái quốc}

Thư nhất, thi đua ái quốc nhằm xây dựng cuộc sống ấm no, hạnh phúc cho mỗi người dân Việt Nam.

Thi đua yêu nước là sự khơi dậy và phát huy tinh thần sáng tạo, ý thức trách nhiệm của mọi tầng lớp nhân dân nhằm thực hiện tốt hơn công việc của cách mạng và công việc hàng ngày. Thi đua yêu nước, trong bản chất của nó, có khả năng cải tạo và xây dựng con người. Nội dung cốt lõi trong Lời kêu gọi thi đua ái quốc mang đậm giá trị nhân văn cao đẹp, đó là thi đua vì "con người", vì sự sinh tồn và phát triển của mỗi người dân và cả dân tộc Việt Nam. Theo đó, "diệt giặc" là mục đích của thi đua ái quốc: Giặc đói và giặc dốt chính là giặc nội xâm, cùng với diệt giặc ngoại xâm để bảo vệ quyền thiêng liêng nhất của mỗi người dân việt Nam đó là quyền sống, quyền tự do và quyền mưu cầu hạnh phúc. Điểm nhấn trong hệ giá trị nhân văn đó được biểu hiện ngay trong thứ tự sắp xếp nội dung thi đua ái quốc, đó là: Diệt giặc đói trước (để cứu mạng sống của người dân); diệt giặc dốt (để nâng cao dân trí); đồng thời, diệt giặc ngoại xâm để bảo vệ Tổ quốc. Như vậy, thi đua ái quốc không chỉ hướng đích đến việc nâng cao đời sống và sự hiểu biết của người dân; mà còn hướng cho nhân dân đoàn kết đấu tranh bảo vệ chính nghĩa, chống lại sự áp bức, nô dịch, xâm lược của thực dân Pháp.

Trong bối cảnh giặc đói, giặc dốt hoành hành khắp cả nước; giặc ngoại xâm đô hộ, tàn bạo và dã tâm lật đổ chính quyền cách mạng non trẻ của đất nước. Chủ tịch Hồ Chí Minh đã kịp thời nắm bắt được tình hình, kêu gọi và dẫn dắt toàn dân tộc đứng lên đấu tranh giành quyền sống cho đồng bào; quyền được học tập và tự do ngôn luận. Đồng thời, hiệu triệu toàn dân đứng lên đấu tranh xoá bỏ những tàn dư lạc hậu, thậm 
chí cả những nọc độc, đầu độc tinh thần của thực dân Pháp đối với người dân Việt Nam; xóa bỏ chủ nghĩa vị kỷ, hưởng lạc, chủ nghĩa cá nhân cực đoan, lối sống tư sản. Giá trị nhân văn cao đẹp ấy đã dần thấm sâu vào nhận thức của mỗi người dân, tạo sự lan tỏa và trở thành động lực tinh thần to lớn góp phần đưa đất nước vượt qua những khó khăn: Nạn đói dần được đẩy lùi; người dân biết đọc, biết viết và có sự hiểu biết đầy đủ hơn; yếu tố vật chất, tinh thần phục vụ cho cuộc kháng chiến chống xâm lược được nâng cao.

Thí hai, thi đua ái quốc góp phần bồi dưỡng đạo đức cách mạng cho mỗi người dân Việt Nam.

Chiều sâu trong đạo đức cách mạng là bản chất nhân văn sâu sắc được biểu hiện trong Lời kêu gọi thi đua ái quốc, đó là sự trung thành vô hạn với Tổ quốc, thi đua để "diệt giặc ngoại xâm". Đồng thời, thi đua ái quốc phải thực sự trở thành phong trào sôi nổi, rộng khắp để mọi người dân ra sức thi đua lao động sản xuất gắn liền với thực hành tiết kiệm trong tiêu dùng để có "đầy đủ lương thực, khí giới, để giết giặc ngoại xâm". Điểm nhấn trong bồi dưỡng đạo đức cách mạng là rèn luyện tính trung thực cho con người Việt Nam, điều này được thể hiện ngay trong từng công việc hàng ngày "làm cho mau", "làm cho tốt", "làm cho nhiều". Tính trung thực là nội dung cốt lõi trong hệ giá trị đạo đức của con người Việt Nam, là biểu hiện đạo lý làm người, là thước đo giá trị văn hóa, là dũng khí tự phê bình và phê bình, được nâng tầm trở thành đạo đức cách mạng với bốn chuẩn mực: Cần, kiệm, liêm, chính và hai nguyên tắc ứng xử đạo đức: Chí công, vô tư. Vì thế, mọi người dân Việt Nam đều phải ra sức thi đua để bồi dưỡng đạo đức cách mạng phục vụ sự nghiệp kháng chiến, kiến quốc của dân tộc.

Giá trị nhân văn còn được biểu hiện trong sự gắn kết giữa mục tiêu thi đua với những hoạt động thiết thực hàng ngày, ở từng lứa tuổi, trong từng chuyên môn, làm cho giá trị nhân văn cao đẹp ấy thấm sâu vào tâm tư, tình cảm của mỗi người dân, góp phần bồi đắp lý tưởng cách mạng, nuôi dưỡng hoài bão "Người đi trước hiểu biết, dẫn dắt người đi sau, làm cho mọi người cùng tiến bộ". Thi đua ái quốc còn là hoạt động mang tầm tư tưởng và tinh thần là biểu hiện của sự đoàn kết dân tộc và đoàn kết quốc tế. Vì thế, thi đua phải đoàn kêt, đoàn kết để đẩy mạnh thi đua, phải thân ái giúp đỡ nhau tạo nên phong trào sôi nổi, làm cho thi đua ái quốc ăn sâu, lan rộng về mọi mặt vào mọi tầng lớp nhân dân, cùng nhau vượt qua mọi khó khăn, giành nhiều thắng lợi.
Thư $b a$, thi đua ái quốc là để thực hiện dân chủ xã hội chủ nghĩa.

Dân chủ trong Lời kêu gọi thi đua ái quốc là giá trị nhân văn cao đẹp được biểu hiện đậm nét ở việc "trọng dân". Thi đua phải dựa vào lực lượng của dân, tinh thần của dân, để gây hạnh phúc cho nhân dân. Thi đua phải đặt nhân dân vào vị trí trung tâm; coi trọng và thấu hiểu nhân dân; chăm lo, bồi dưỡng và tiết kiệm sức dân để nhân dân có đủ cơm ăn, áo mặc, được học hành, được tự do ngôn luận, được hưởng những quyền lợi chính đáng, thiết thân.

Giá trị nhân văn cao đẹp còn được biểu hiện ở việc “tin dân", tin tưởng vào lực lượng, trí tuệ và tỉnh thần của nhân dân; tin vào khả năng và sức mạnh to lớn của nhân dân trong sự nghiệp chống đói nghèo, lạc hậu, chống giặc ngoại xâm; tin vào tương lai tươi sáng của đất nước. Đó là mục tiêu cao nhất của Đảng; là khát vọng, hoài bão lớn nhất của nhân dân; là giá trị cốt lõi xuyên suốt trong hệ giá trị nhân văn của dân tộc, là sức mạnh nội sinh; là lực đẩy của phát triển và tính hướng đích của tiến bộ xã hội.

Giá trị nhân văn còn được biểu hiện ở chỗ gắn trách nhiệm với quyền lợi, bổn phận của người dân; gắn hoạt động thực tiễn của người dân với bổn phận, trách nhiệm của từng công dân "bất kỳ sĩ, nông, công, thương, binh; bất kỳ làm việc gì, đều cần phải thi đua", để: "Toàn dân đủ ăn, đủ mặc. Toàn dân sẽ biết đọc biết viết. Toàn bộ đội sẽ đầy đủ lương thực, khí giới, để giết giặc ngoại xâm", để tiến tới "Dân tộc độc lập. Dân quyền tự do. Dân sinh hạnh phúc". Vì vậy, thi đua ái quốc cần dựa chắc vào dân, thấu hiểu dân tình, chăm lo dân sinh, nâng cao dân trí để thực hành dân chủ.

\subsection{Vận dụng trong giáo dục đạo đức cách mạng cho} thanh niên hiện nay

Tám mươi năm kể từ ngày Chủ tịch Hồ Chí Minh ra Lời kêu gọi thi đua ái quốc, những giá trị nhân văn cao đẹp ấy đã dần thấm sâu vào mỗi trái tim, khối óc của người dân Việt Nam, tạo thành động lực tinh thần và sức mạnh to lớn để cách mạng Việt Nam giành được nhiều thành tựu to lớn có ý nghĩa lịch sử. Trong sự nghiệp công nghiệp hóa, hiện đại hóa và hội nhập quốc tế, cùng với mọi giai tầng trong xã hội, Đảng Cộng sản Việt Nam tiếp tục khẳng định: Thanh niên luôn giữ vị trí trung tâm trong chiến lược phát huy nhân tố và nguồn lực con người. Chăm lo, phát triển thanh niên vừa là mục tiêu, vừa là động lực bảo đảm cho sự ổn định và phát triển vững bền của 
đất nước. Vấn đề đặt ra trong việc giáo dục đạo đức cách mạng cho thanh niên, công tác thi đua cần phải:

Một là, thi đua hướng vào giáo dục lý tưởng cách mạng cho thanh niên.

Giáo dục lý tưởng cách mạng cho thanh niên là một nhiệm vụ chiến lược của cách mạng. Tăng cường giáo dục lý tưởng cách mạng góp phần xây dựng bản lĩnh chính trị, kiên định, vững vàng, tin tưởng tuyệt đối vào sự lãnh đạo của Đảng “Tăng cường giáo dục lý tưởng, đạo đức cách mạng, lối sống văn hóa, ý thức công dân để hình thành thế hệ thanh niên có phẩm chất tốt đẹp, có khí phách và quyết tâm hành động thực hiện thành công sự nghiệp công nghiệp hóa, hiện đại hóa" $[1$, tr. 45]. Vì vậy, công tác thi đua phải hướng cho thanh niên tạo dựng được niềm tin, ý chí tự lực, tự cường, khát vọng vươn lên vượt qua mọi khó khăn, thử thách để khẳng định mình, biến ước mơ, hoài bão thành hiện thực; không ngừng học tập chiếm lĩnh những đỉnh cao mới của tri thức, năng động sáng tạo áp dụng những thành tựu đó vào thực tiễn công tác; rèn luyện bản lĩnh chính trị, tư tưởng, đạo đức, nhân cách; tích cực đấu tranh bảo vệ chủ nghĩa Mác - Lênin, tư tưởng Hồ Chí Minh, đường lối quan điểm của Đảng; có đủ khả năng để "miễn dịch" và “đề kháng” trước sự cám dỗ, ảnh hưởng tiêu cực ngoài xã hội, giữ vững bản lĩnh chính trị, lý tưởng cao đẹp, sẵn sàng nhận và hoàn thành tốt mọi nhiệm vụ được giao "Khuyến khích, cổ vũ thanh niên nuôi dưỡng ước mơ, hoài bão, xung kích, sáng tạo" [2, tr.162].

Để thực hiện được mục tiêu trên, các cấp ủy đảng, chính quyền và các tổ chức đoàn cần chú trọng giáo dục chính trị, tư tưởng cho đoàn viên, thanh niên, phát huy truyền thống cách mạng, khơi dậy lòng yêu nước, bồi đắp tinh thần tự hào dân tộc cho thanh niên; định hướng cho đoàn viên, thanh niên xác định được những giá trị chuẩn mực về đạo đức, lối sống và phương pháp ứng trong quan hệ xã hội. Xác định rõ nội dung, biện pháp bồi dưỡng mục tiêu, lý tưởng cách mạng cho thanh niên. Tổ chức phân công cán bộ, đảng viên có uy tín, trách nhiệm theo dõi, giúp đỡ thanh niên trong học tập và rèn luyện. Kết hợp giáo dục, bồi dưỡng lý tưởng cách mạng với giải quyết hài hòa các vấn đề về lợi ích chính đáng của thanh niên như: học tập, lao động, rèn luyện, nhu cầu văn hoá thông tin, giải trí tạo môi trường để thanh niên rèn luyện, phấn đấu và phát triển toàn diện. Cấp ủy đảng, tổ chức đoàn cần tăng cường kiểm tra, nắm chắc số lượng, chất lượng, tình hình tư tưởng, tâm tư nguyện vọng của thanh niên để giải quyết kịp thời những vấn đề nảy sinh. Chủ động phát hiện những điển hình tiên tiến để có kế hoạch bồi dưỡng, giúp đỡ thanh niên phấn đấu. Nội dung bồi dưỡng phải toàn diện, chú trọng bồi dưỡng lý tưởng cách mạng, phẩm chất, năng lực, động cơ thi đua "Đổi mới nội dung phương thức giáo dục chính trị, tư tưởng, lý tưởng, truyền thống, bồi dưỡng lý tưởng cách mạng, lòng yêu nước, xây dựng đạo đức, lối sống lành mạnh" [3, tr. 162].

Hai là, thi đua hướng vào xây dựng tinh thần đoàn kết, ý thức trách nhiệm cho thanh niên.

Xây dựng tinh thần đoàn kết vừa là chuẩn mực đạo đức cách mạng, vừa là nhân tố cơ bản để xây dựng cơ quan, đơn vị vững mạnh toàn diện. Vì vậy, công tác thi đua phải hướng cho thanh niên xây dựng tinh thần đoàn kết trên lập trường giai cấp công nhân vì mục tiêu độc lập dân tộc và chủ nghĩa xã hội; chú trọng bồi dưỡng tình yêu thương đồng chí, tôn trọng lẫn nhau. Xây dựng tinh thần nhân ái, lạc quan, tạo sự đồng thuận trong quan hệ xã hội. Chú trọng bồi dưỡng phương pháp chỉ đạo hoạt động thực tiễn cho thanh niên.

Để thực hiện được mục tiêu trên, cấp ủy đảng, chính quyền và đoàn thể các cấp cầnđẩy mạnh công tác tuyên truyền, nâng cao nhận thức trách nhiệm của thanh niên, phát huy vai trò xung kích sáng tạo, tinh thần tự lực, tự cường, khơi dậy lòng tự hào dân tộc, tạo môi trường thuận lợi để thanh niên phấn đấu rèn luyện. Các cấp bộ đoàn cần chủ động và không ngừng đổi mới phương pháp để tổ chức cho thanh niên tích cực tham gia vào các phong trào: "Thanh niên với nhiệm vụ bảo vệ Tổ quốc"; "Tuổi trẻ giữ nước"; "Nghĩa tình biên giới, hải đảo"; "Vì Trường Sa thân yêu"; "xóa đói giảm nghèo"; thực hiện tốt cuộc vận động "Phát huy truyền thống, cống hiến tài năng, xứng danh Bộ đội Cụ Hồ”, để thanh niên học tập, rèn luyện, cống hiến tài năng và sức trẻ phục vụ cho sự nghiệp cách mạng của Đảng. Đồng thời, phải tăng cường giáo dục tinh thần cảnh giác cách mạng, kiên quyết đấu tranh với những quan điểm sai trái, thù địch, giữ gìn môi trường hòa bình, ổn định để hội nhập và phát triển đất nước theo định hướng xã hội chủ nghĩa.

$B a$ là, thi đua hướng vào xây dựng nếp sống tự tôn pháp luật, ý thức chấp hành kỷ luật cho thanh niên.

Pháp luật và đạo đức cùng hướng đến điều chỉnh hành vi, ứng xử của thanh niên phù hợp với quy định của pháp luật và các chuẩn mực đạo đức xã hội. Do đó, công tác thi đua phải hướng vào giáo dục ý thức tự 
tôn pháp luật cho thanh niên, phát huy tính tự giác trong học tập, rèn luyện để hình thành động cơ, thái độ đúng đắn, tăng cường giáo dục "ý thức tôn trọng và nghiêm chỉnh chấp hành Hiến pháp và pháp luật cho thế hệ trẻ" [4, tr. 162].Tạo mọi điều kiện thuận lợi để thanh niên phấn đấu, rèn luyện; tăng cường kiểm tra, đánh giá và định hướng cho thanh niên phấn đấu. Tin tưởng giao nhiệm vụ phù hợp với năng lực, sở trường của thanh niên, định hướng cho thanh niên luôn giữ vững niềm tin trong cuộc sống; xác định rõ trách nhiệm, sống có lý tưởng, hoài bão, khát vọng vươn tới cái mới, cái tiến bộ.

\section{Kết luận}

Lời kêu gọi thi đua ái quốc của Chủ tịch Hồ Chí Minh đã đi vào lịch sử của dân tộc Việt Nam như một chân lý. Trong công cuộc đổi mới, hội nhập và phát triển, giá trị nhân văn trong Lời kêu gọi thi đua ái quốc vẫn luôn là nền tảng, động lực tinh thần to lớn, lôi cuốn đông đảo mọi tầng lớp nhân dân, mọi thành phần kinh tế, các tổ chức đoàn thể và ban ngành trong xã hội tích cực tham gia. Chúng ta tin tưởng chắc chắn rằng, với tinh thần thi đua yêu nước của toàn dân tộc, với sự hợp tác giúp đỡ của bạn bè quốc tế, sự nghiệp đổi mới, công nghiệp hóa, hiện đại hóa và hội nhập quốc tế của nước nhà nhất định sẽ thành công, góp phần thực hiện thắng lợi Di chúc của Người, xây dựng nước Việt Nam giàu mạnh, xã hội công bằng, văn minh.

\section{TÀI LIỆU THAM KHẢO}

1. Đảng Cộng sản Việt Nam (2008), Văn kiện Hội nghi lần thứ bảy Ban Chấp hành Trung uoong khóa X, Nxb CTQG, H, tr.45;

2. Đảng Cộng sản Việt Nam (2016), Văn kiện Đại hội đại biểu toàn quốc lần thư XII, NxbCTQG Sự Thật, H, tr.162;

3.Hồ Chí Minh (2011), Toàn tập, tập 5, Nxb CTQG, $\mathrm{H}, \mathrm{tr} .144$;

4. Hồ Chí Minh (2011), Toàn tập, tập 6, Nxb CTQG, $\mathrm{H}, \operatorname{tr} .473$;

5. Hồ Chí Minh (2011), Toàn tập, tập 12, Nxb CTQG, H, tr. 774 .

\section{The noble human values in the call of national patriotism with the role of educating moral of today youth generation}

Bui Bach Dang, Tran The Khanh

\section{Article info}

\section{Recieved:}

20/4/2018

Accepted:

$10 / 9 / 2018$

Keywords:

Ho Chi Minh, patriotic competition, human values.

\begin{abstract}
80 years ago, between the hardships, fierce in the resistance against the French colonial invasion, At the initiative of President Ho Chi Minh, in March 27, 1948, The Party Central Committee promulgated the Directive to foster the national patriotism movement in order to encourage all forces participating in the resistance. In June 11, 1948, President Ho Chi Minh issued raised a call for patriotic emulation. This is an immortal epic, it contains deep and profound human values.
\end{abstract}

